\title{
Plasma Exchange for Neuroborreliosis Associated with Guillain Barre Syndrome
}

\section{Elleuch A*, Loukil M, Hsairi M, Feki M, Gargouri L and Mahfoudh A}

Department of Pediatrics, Pediatric Emergency and Intensive Care, Hedi Chaker, University Hospital, Sfax, Tunisia

${ }^{*}$ Corresponding author: Elleuch A, Department of Pediatrics, Pediatric Emergency and Intensive Care, Hedi Chaker, University Hospital, Sfax, Tunisia, Tel: +216-20-935-602, E-mail: amalelleuch@gmail.com

Citation: Elleuch A, Loukil M, Hsairi M, Feki M, Gargouri L, et al. (2021) Plasma Exchange for Neuroborreliosis Associated with Guillain Barre Syndrome. J Case Rep Stud 9(1): 101

Received Date: March 09, 2021 Accepted Date: June 21, 2021 Published Date: June 23, 2021

\begin{abstract}
Lyme neuroborreliosis (LNB) is a rare infectious disorder of the nervous system caused by Borrelia burgdorferi spirochetes. Different neurological conditions were reported in the disease.

We report a case of LNB in a 4-year-old boy with abdominal pain as first symptom and following onset of symmetrical ascending progression of weakness causing severe respiratory failure. The patient was diagnosed initially with GuillainBarre syndrome (GBS). Despite the fact that he had received Intravenous immunoglobulin (IVG) treatment, upper and lower muscle weakness and respiratory failure did not recover. Second dose of IVG treatment was started but the patient didn't get better. Diagnosis of LNB was made by detection of specific antibody in serum with neuro-radiological images suggestive for this infectious disease. After a 2- week course of third-generation cephalosporin, the outcome was favorable with improvement in muscle tone but persistence of respiratory muscle failure with two extubation failures. Therefore administration of plasmapheresis was decided. All symptoms relieved following this treatment.

Conclusion: This case report shows that Pediatricians must consider Lyme disease in the differential diagnosis of GBS, especially in countries where the infection is endemic. This case shows that plasmapheresis could be effective for pediatric neuroborreliosis cases.
\end{abstract}

Keywords: Lyme Neuroborreliosis; Lyme Disease; Guillain-Barre Syndrome; Plasmapheresis; Children 


\section{Introduction}

Lyme neuroborreliosis (LNB) is caused by infection with Borrelia burgdorferi (Bb) and transmitted to human by a tick bite [1]. Neuroborreliosis (NB) is a manifestation of Lyme disease, which the issue is almost favorable if adequate antibiotic treatment is administered. Although, in 15\% of pediatric patients some permanent neurological deficits are found [2].

As neuroborreliosis is known to mimic many neurological conditions, it is an important differential to bear in mind and should be investigated as part of the initial work up as appropriate treatment can be started without delay.

We present a case of LNB in order to emphasize the neurological manifestations of this disease and that plasmapheresis could be a valuable alternative for pediatric NB cases.

\section{Case presentation}

Our patient also received intensive neurorehabilitation. The notion of a tick bite or erythema migrans has not been reported elsewhere.

This about a 4-year-old child. Ten days before his admission to intensive care unit; he presented a history of gastroenteritis and abdominal pain. Over the next few days, there was a walking disorder which rapidly worsened towards a symmetrical ascending progression of weakness responsible for severe respiratory failure which required his mechanical ventilation. The patient has no fever, presented axial and peripheral hypotonia. All the muscle stretch reflexes were absent. There was no sign of meningism, no rash, no photophobia neither neck stiffness. The patient's initial blood tests including inflammatory markers were normal: The $\mathrm{C}$ reactive protein level was $5 \mathrm{mg} / \mathrm{l}$ and the erythrocyte sedimentation rate was $10 \mathrm{~mm} / \mathrm{h}$. A head CT on admission was normal, and a subsequent MRI of the spine showed no nerve root compression. Guillain Barré syndrome (GBS) has been suspected. He had a lumbar puncture after 6 days from the onset of the symptoms. Cerebrospinal fluid (CSF) showed a white cell count of 3 cells/ $\mu$, a normal protein count of $0.15 \mathrm{~g} / \mathrm{l}(0,32 \pm 0,2 \mathrm{~g} / \mathrm{l})$ and normal glucose of $7.36 \mathrm{mM} / \mathrm{l}$ (50 to $75 \%$ of blood sugar). Nerve conduction studies showed a slow nerve conduction velocities and delayed F-waves, suggestive of a demyelinating neuropathy. The patient was initially given 5 days of IVG $(0.4 \mathrm{~g} / \mathrm{kg} /$ day $)$ for suspected GBS. This treatment did not make the expected improvement in his condition. On the 5th day of his hospitalization, the patient presented a fever and a seizure. The CSF showed 20 white cells, protein count of 0.32 and glucose of 4.51 . The electroencephalogram showed severe brain pain. Second dose of IVG treatment was started for 5 days $(0.4 \mathrm{~g} / \mathrm{kg} /$ day $)$ but the patient didn't get better. As part of the differential diagnosis, the Lyme disease serology, was performed. Both IgG and IgM antibodies to Borrelia were positive in the blood and the CSF. Western blot confirmed Lyme disease. Treatment was started for LNB based on Ceftriaxone with a mild improvement after 15 days. Hence, the administration of plasmapheresis was decided. The dosage is 200-250 cc per kilogram weight of patient every other day for a total of six treatments. The majority of the symptoms regress following the plasmapheresis.

The patient was discharged home after 2 months and 15 days of hospitalization. Six weeks following the completion of his antibiotics, from being completely bed bound with quadriparesis, he was mobilizing with a stick. He was offered regular physiotherapy to help regain full function.

\section{Discussion}

Lyme disease is a multisystem widespread bacterial infection because of the important risk of exposure to tick bites and low adherence to protective measures [3].

The incidence of this disease may have been underestimated in the pediatric population [4]. Fever, headache, fatigue, and skin rash are typical symptoms of the disease. In the later stages, joints, heart, and the central nervous system are the most affected organs [5]. The neurological system may be involved in the disseminated state. LNB is often a consequence of a delay in requesting serological tests, and therefore treatment.

The pathogenesis of Lyme neuroborreliosis has not been precisely understood. Direct invasion of spirochetes to neurons, glia, and Schwann cells may give rise to damage to the neurological system. Also, the invasion of CSF by Borrelia triggers an inflammatory response in the central nervous system, manifesting with the characteristic symptoms of LNB [6]. 
In pediatric population, many neurologic disorders associated with the Lyme disease have been reported [2,7-10]. The classical clinical manifestations are lymphocytic meningitis, radiculoneuritis and cranial neuritis [11]. The patient in this case hadn't develop facial paralysis which is a common feature of LNB but not constant [12].

In the literature, both GBS and Guillain-Barre-like syndrome were described [7,13]. We still don't know whether we are looking at GBS following an immune response triggered by Lyme disease, or if it's Lyme disease mimicking GBS, or, indeed, if the two coexisted.

It was seen that antibiotic therapy and IVG treatment are efficient in Guillain-Barre pediatric cases triggered by B. burgdorferi [11].There are very few cases in the literature about neuroborreliosis mimicking GBS $[11,14]$.

Initially, our patient presented with signs and symptoms that progressed in the manner of Guillain-Barré; the ascending paralysis areflexia and respiratory failure. An initial lumbar puncture showed normal CSF findings. We would have expected an elevated protein count in Guillain-Barré, but, in early stage, normal CSF protein can be found. Our diagnosis was supported by the nerve conduction study showing demyelinating neuropathy but we also saw early denervation, which was unusual for GBS. Having a poor response to the IVG, we questioned the validity of GBS and explored alternative diagnoses. Lyme disease became a more likely differential diagnosis. The IgM and IgG antibodies against Borrelia were positive, suggesting early disseminated Lyme disease, and we gave the patient a 2-week course of intravenous Ceftriaxone, in addition to the previous IVG, he had received for suspected GBS.

In our case, plasmapheresis was decided to be started after 2 weeks of Ceftriaxone because of persistent respiratory failure and average recovery of muscular force. After 6 sessions, upper extremity muscle strength was $4 / 5$, lower extremity muscle strength was $4 / 5$. Our patient was extubated and discharged home.

In literature, there are almost no publications on plasmapheresis treatment in children with Guillain- Barre syndrome arising from B. burgdorferi. Celik et al [7] reported recently a case of 15-year-old patient diagnosed with Lyme neuroborreliosis, who did not recover after immunoglobulin and 4 weeks of Ceftriaxone, however all symptoms relieved following the plasmapheresis. Plasmapheresis can be effective in pediatric neuroborreliosis who did not respond to classic antibiotics.

\section{Conclusion}

This case highlights the importance of bearing differential diagnoses in mind when working up patients with neurological conditions. Our patient initially presented with suspected GBS, but further probing and investigation identified a different diagnosis: LNB.

This case highlights that plasmapheresis could be effective for pediatric severe neuroborreliosis cases. 


\section{References}

1. Hengge UR, Tannapfel A, Tyring SK, Erbel R, Arendt G, et al. (2003) Lyme borreliosis. Lancet Infect Dis 3: 489-500.

2. Skogman BH, Croner S, Nordwall M, Eknefelt M, Ernerudh J, et al. (2008) Lyme Neuroborreliosis in Children: A Prospective Study of Clinical features, Prognosis, and Outcome. Pediatr Infect Dis J 27: 1089-94.

3. Gueorguiev Penev D, Laurent E, Baron S, Diot E, Bastides F, et al. (2010) Lyme borreliosis: census of adult cases hospitalized in Indre-et-Loire, from the PMSI (1999-2006) [Borréliose de Lyme : recensement des cas adultes hospitalisés en Indre-et-Loire, à partir du PMSI (1999-2006)]. Rev DÉpidémiologie Santé Publique 58: 339-47.

4. Huppertz HI, Bartmann P, Heininger U, Fingerle V, Kinet M, et al. (2012) Rational diagnostic strategies for Lyme borreliosis in children and adolescents: recommendations by the Committee for Infectious Diseases and Vaccinations of the German Academy for Pediatrics and Adolescent Health. Eur J Pediatr 171: 1619-24.

5. Mead PS (2015) Epidemiology of Lyme Disease. Infect Dis Clin North Am 29: 187-210.

6. Rupprecht TA, Koedel U, Fingerle V, Pfister H-W (2008) The Pathogenesis of Lyme Neuroborreliosis: From Infection to Inflammation. Mol Med 14: 205-12.

7. Çelik T, Çelik Ü, Kömür M, Tolunay O, Dönmezer Ç, et al. (2016) Treatment of Lyme neuroborreliosis with plasmapheresis: Plasmapheresis in Pediatric Neuroborreliosis. J Clin Apheresis 31: 476-8.

8. Savasta S, Fiorito I, Foiadelli T, Pichiecchio A, Cambieri P, et al. (2020) Abdominal pain as first manifestation of lyme neuroborreliosis in children, case report and review of literature. Ital J Pediatr 46.

9. Din F, Agarwal N, Mahfooz N, Hafeez MU, Ahmad R, et al. (2016) Lyme in the coconut: Paediatric neuroborreliosis. J Paediatr Child Health 52: 1042-3.

10. Rožic M, Lah LL, Ružic-Sabljic E, Kastrin A, Arnež M (2019) Lyme Neuroborreliosis in Children: Etiology and Comparison of Clinical Findings of Lyme Neuroborreliosis Caused by: Borrelia garinii: and: Borrelia afzelii. Pediatr Infect Dis J 38: e279-e284.

11. Owens J, Filatov A, Hussain-Wilson S (2020) Guillain-Barre Syndrome, Neuroborreliosis, or Both. Cureus 12: e7823.

12. Guet-Revillet H, Levy C, Vallet C (2019) Lyme neuroborreliosis in children: Report of nine cases and a review of the literature. Arch Pediatr 26: 133-7.

13. Horneff G, Huppertz H-I, Müller K, Voit T, Karch H (1993) Demonstration of Borrelia burgdorferi infection in a child with Guillain-Barré syndrome. Eur J Pediatr 152: 810-2.

14. Tyagi N, Maheswaran T, Wimalaratna S (2015) Neuroborreliosis: the Guillain-Barré mimicker. Case Rep 2015: bcr2014209080. 


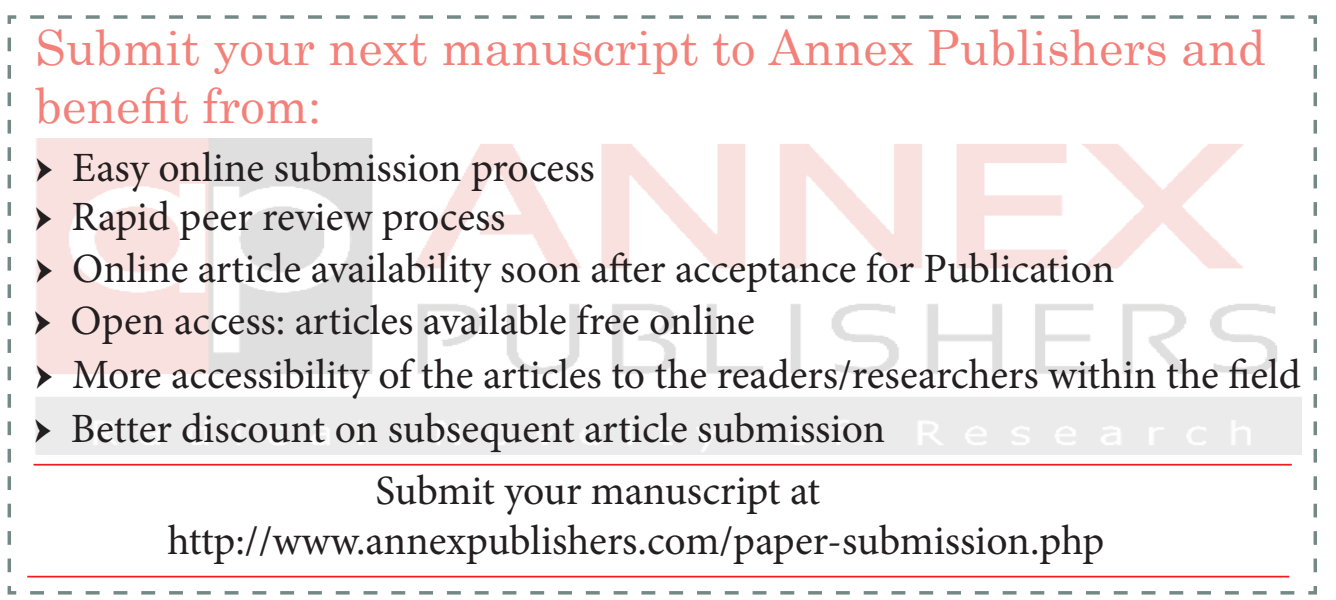

